\title{
Experimental Investigation and Finite Element Analysis for Mechanical Behavior of Steel-concrete Composite Beams under Negative Bending
}

\author{
Y. LIU ${ }^{\mathrm{a}}$, B. SUN \\ State Key Laboratory for Disaster Reduction in Civil Engineering, Tongji University, Shanghai, \\ 200092, China
}

aliuyang821127@163.com, bsunbo62@sina.com

${ }^{*}$ Corresponding author

\begin{abstract}
Keywords: Steel-concrete Composite Beams, Negative Bending, Bending Bearing Capacity, Finite Element Analysis.
\end{abstract}

\begin{abstract}
Experiments on four steel-concrete composite beams under negative bending were carried out in this paper. The effects of three factors such as bending moment ratio between two ends of a beam, height-to-thickness ratio of web, lateral slenderness ratio of compressive flanges on the bending bearing capacity $M_{\mathrm{u}}$ of composite beams were investigated. The experimental results indicate that $M_{\mathrm{u}}$ and $M_{\mathrm{u}} / M_{\mathrm{p}}$ decrease as bending moment ratio between two ends of a beam increases, and $M_{\mathrm{p}}$ is cross-section plastic moment of composite beam. $M_{\mathrm{u}}$ is less affected by heightto-thickness ratio of web. However, $M_{\mathrm{u}} / M_{\mathrm{p}}$ decreases as height-to-thickness ratio of web increases. If lateral slenderness ratio of compressive flanges is large, $M_{\mathrm{u}}$ and $M_{\mathrm{u}} / M_{\mathrm{p}}$ are less affected by lateral slenderness ratio of compressive flanges. Finally, the finite element models of four composite beams under negative bending were established. The calculated results agree well with the experimental results.
\end{abstract}

\section{Introduction}

Steel - concrete composite beam is a kind of reasonable and economical construction member of high strength and low cost. At the same time, composite beam by the negative bending can encounter distortional buckling failure mode which is different from buckling of the steel beams. so it's now attracting considerable attention on mechanical behavior of steel-concrete composite beams under negative bending.

Daniels et al.[1] studied on bending bearing capacity $M_{\mathrm{u}}$ of composite beams with the compact section in negative moment regions by applying concentrated load at mid-span for two-span continuous composite beam. The results showed that $M_{\mathrm{u}}$ of composite beams with the compact section can reach cross-section plastic moment of composite beam when the lateral slenderness ratio of steel beam is small. Johnson[2] and Bradford[3] studied on distortional lateral buckling of composite beam under negative moment regions by applying uniform load to the two-span continuous beam and proposed that height-to-thickness ratio of web is the major influence on $M_{\mathrm{u}}$. Experiment study on simply supported composite beams by applying concentrated load at mid-span to form negative moment regions by Kemp et al.[4]. It was found from experiment results that height-to-thickness ratio of web, lateral slenderness ratio of compressive flange are the major influence on $M_{\mathrm{u}}$. Zhu P.R. et al.[5] and Fan J.S. et al.[6]conducted experiment of continuous composite beams to analyze internal force redistribution and ductility of the continuous composite beams and presented that the larger force ratio of composite beam, the smaller the ductility of composite beam. Liu Y. et al.[7] studied on the mechanical performance of composite beams under negative moments by finite element analysis and considered that bending moment ratio between two ends of a beam has effect on $M_{\mathrm{u}}$ and ductility of the composite beam. In above experiments, bending moment ratio between two ends of a beam was not investigated.

This paper will present experiments on four steel-concrete composite beams under negative bending were carried out in this paper. The effects of three factors such as bending moment ratio between two ends of a beam, height-to-thickness ratio of web, lateral slenderness ratio of 
compressive flanges on the bending bearing capacity $M_{\mathrm{u}}$ of composite beams were investigated. At the same time, this paper will introduce the finite element models of four composite beams under negative bending and verification of the model.

\section{Experimental Program}

\section{Test Specimens}

A total of four composite beam specimens in Figure 1 were tested under negative bending. As shown in Figure 1, the concrete slab was $800 \mathrm{~mm}$ wide and $100 \mathrm{~mm}$ thick. Two layers of C8 $(8 \mathrm{~mm}$ in diameter) rebars with $200 \mathrm{~mm}$ spacing in the concrete slab longitudinally were provided $15 \mathrm{~mm}$ away from the top and bottom surface of the concrete slab. Two layers of C8 (8mm in diameter) rebars in the concrete slab along the width direction were provided at $250 \mathrm{~mm}$ spacing. Two rows of studs with $16 \mathrm{~mm}$ diameter and $80 \mathrm{~mm}$ long were welded to the top flange with a transverse spacing of $70 \mathrm{~mm}$ and longitudinal spacing of $220 \mathrm{~mm}$ and $300 \mathrm{~mm}$ for the beams with a span of $3 \mathrm{~m}$ and 4.2 $\mathrm{m}$.

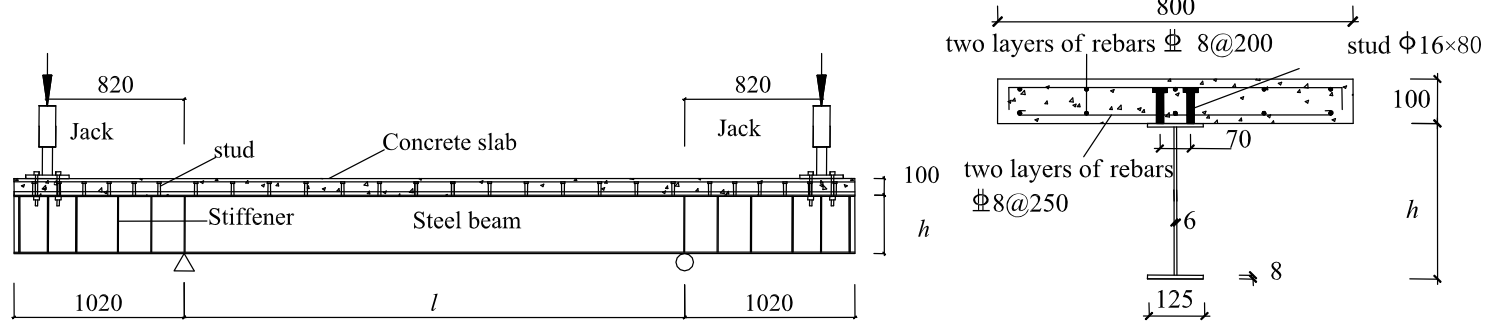

Fig. 1 Geometry of composite beam specimens

As shown in the Table 1 , the test specimens were labelled as $B \square-\bigcirc-\triangle$ " so that the specimen information could be identified from the labels: the B indicated composite beam; The $\square$ "indicated the span of the beam. 4.2 and 3.0 meant $4200 \mathrm{~mm}$ and $3000 \mathrm{~mm}$ respectively; The $\bigcirc$ "indicated the height of the $\mathrm{H}$-shaped cross section. 350 and 400 meant $350 \mathrm{~mm}$ and $400 \mathrm{~mm}$ respectively; The $\triangle$ "indicated the load case. 1 and 0 meant bending moment ratio $M_{2} / M_{1}=1$ and bending moment ratio $M_{2} / M_{1}=0$, respectively.

Tab. 1 Parameters of Test Specimens

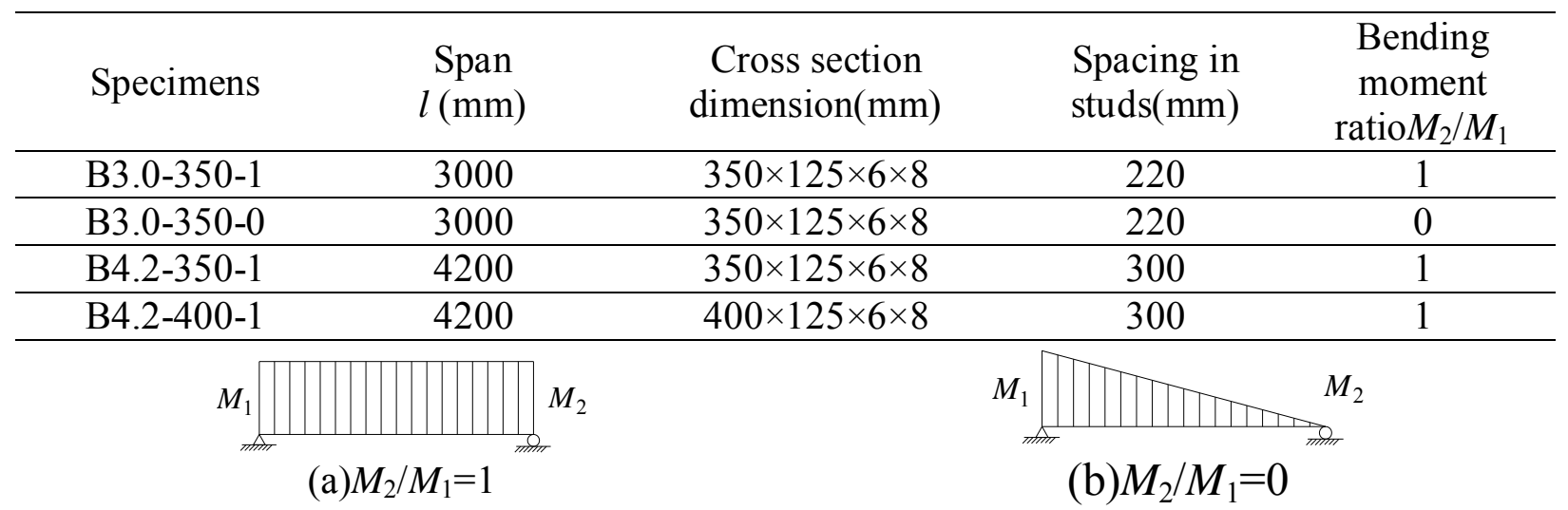

Fig. 2 Bending Moment Cases

The primary parameters were the bending moment ratio between two ends of a beam, height-tothickness ratio of web, lateral slenderness ratio of compressive flanges. The value of primary parameters is setting as the follows:(1)There are two types of bending moment ratio between two ends of a beam in Figure 2.(2)Two kinds of H-shaped section are $350 \mathrm{~mm} \times 125 \mathrm{~mm} \times 6 \mathrm{~mm} \times 8 \mathrm{~mm}$ and $400 \mathrm{~mm} \times 125 \mathrm{~mm} \times 6 \mathrm{~mm} \times 8 \mathrm{~mm}$. The main difference between the two kinds of $\mathrm{H}$ section lies in height-thickness ratio of web $h_{\mathrm{w}} / t_{\mathrm{w}}$. The $h_{\mathrm{w}} / t_{\mathrm{w}}$ of former and latter section are 55.7 and 64.0, 
respectively. (3)There are two kinds of lateral slenderness ratio of compressive flange. The spans $l$ of all the specimens are $3000 \mathrm{~mm}$ and $4200 \mathrm{~mm}$ so that the value of lateral slenderness ratio $l / r_{\mathrm{y}}$ of compressive flanges is 83.1 and 116.4 respectively. $r_{\mathrm{y}}$ is the radius of gyration of compressive flange along y direction.

\section{Material}

Mechanical properties of steel, rebar and concrete are given in Table 2.

Tab. 2 Mechanical Properties of Steel, Rebar and Concrete

\begin{tabular}{cccc}
\hline Element & $f_{\mathrm{y}}(\mathrm{MPa})$ & $f_{\mathrm{u}}(\mathrm{MPa})$ & $f_{\mathrm{cu}}(\mathrm{MPa})$ \\
\hline Steel web & 362 & 489 & - \\
\hline Steel flange & 403 & 522 & - \\
\hline Rebar & 530 & 657 & - \\
\hline Concrete slab & - & - & 25.1 \\
\hline
\end{tabular}

Notes: $f_{\mathrm{y}}$ is yield strength of steel; $f_{\mathrm{u}}$ is tensile strength of steel; $f_{\mathrm{cu}}$ is compressive strength of concrete

\section{Instrumentation and Test Rigs}

Stress of the rebar in the concrete slab, flange and web of the steel beam were recorded by means of strain gauges for revelation of any possible local buckling of the I-beam at the middle span and the support. Besides, vertical and lateral displacement of the beam was recorded through displacement transducers at the end support, one-half and one-quarter points of the beam for investigation of any possible distortional buckling of the whole beam. Besides, the end rotation angle of the beam was recorded by rotation angle indictor, and then the rotation capacity of the beam can be defined through the end moment-rotation curve.

\section{Experimental Results}

\section{Moment-rotation Curves and Characteristic Values of Moments}

Moment-rotation curves of composite beam specimens are drawn in Figure 3 . In the curve $M_{\mathrm{cr}}$ is concrete -cracked moment; $M_{\mathrm{y}}$ is the moment that bottom flange of steel beam reaches the yield point; $M_{\mathrm{u}}$ is the bending bearing capacity of composite beam; $M_{\mathrm{p}}$ is cross-section plastic moment of composite beam. Fig.3 illustrates applied moment $M$ increases until the $M$ reaches $M_{\mathrm{u}}$ where distortional buckling or local buckling of specimens occur; $M$ decreases after the $M$ reaches $M_{\mathrm{u}}$.

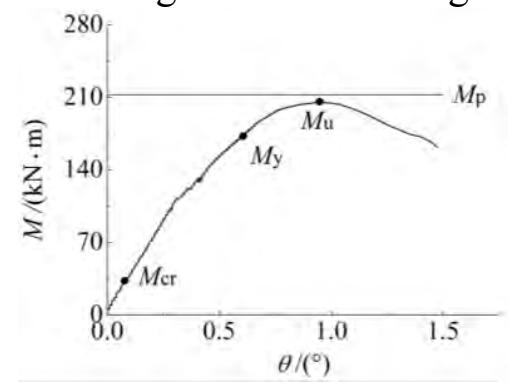

(a) Specimen B3.0-350-1

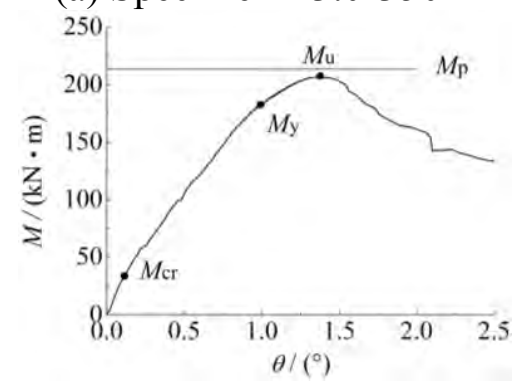

(c) Specimen B4.2-350-1

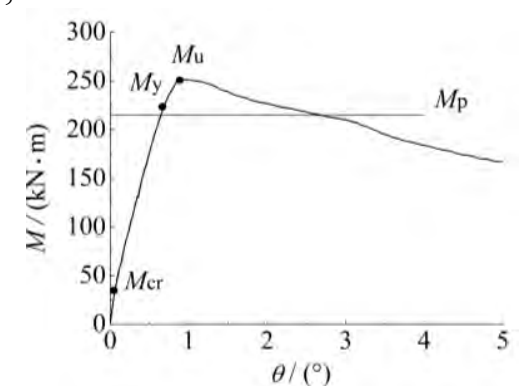

(b) Specimen B3.0-350-0

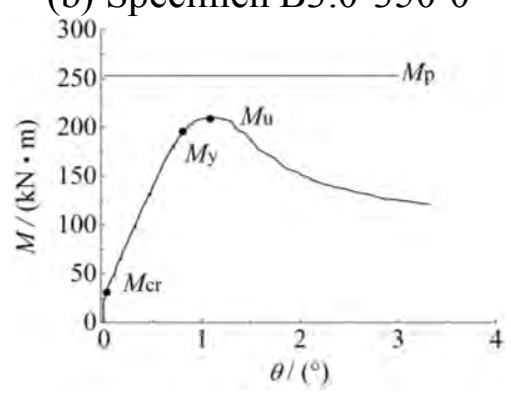

(d) Specimen B4.2-400-1

Fig. 3 Moment-rotation Curves of Composite Beam Specimens 
Characteristic values of moments are given in Table 3. It can be seen that $M_{\mathrm{cr}}$ of all the specimens have similar value; $M_{\mathrm{cr}} / M_{\mathrm{u}}$ of all the specimens are roughly $0.15 ; M_{\mathrm{y}} / M_{\mathrm{u}}$ of all the specimens are roughly 0.85 .

Tab.3 Characteristic Values of Moments of Composite Beam Specimens

\begin{tabular}{cccccccc}
\hline specimen & $\begin{array}{c}M_{\mathrm{cr}} \\
(\mathrm{kN} \cdot \mathrm{m})\end{array}$ & $\begin{array}{c}M_{\mathrm{y}} \\
(\mathrm{kN} \cdot \mathrm{m})\end{array}$ & $\begin{array}{c}M_{\mathrm{u}} \\
(\mathrm{kN} \cdot \mathrm{m})\end{array}$ & $\begin{array}{c}M_{\mathrm{p}} \\
(\mathrm{kN} \cdot \mathrm{m})\end{array}$ & $M_{\mathrm{cr}} / M_{\mathrm{u}}$ & $M_{\mathrm{y}} / M_{\mathrm{u}}$ & $M_{\mathrm{u}} / M_{\mathrm{p}}$ \\
\hline B3.0-350-1 & 32.9 & 173.0 & 205.1 & 212.2 & 0.16 & 0.84 & 0.97 \\
\hline B3.0-350-0 & 32.9 & 226.2 & 251.5 & 214.7 & 0.13 & 0.90 & 1.17 \\
\hline B4.2-350-1 & 32.9 & 180.5 & 206.9 & 213.9 & 0.16 & 0.87 & 0.97 \\
\hline B4.2-400-1 & 32.9 & 196.9 & 210.5 & 253.3 & 0.16 & 0.94 & 0.83 \\
\hline
\end{tabular}

\section{Influence of Parameters on $M_{u}$ and $M_{u} / M_{p}$}

Table 3 also illustrates the Influence of parameters on $M_{\mathrm{u}}$ and $M_{\mathrm{u}} / M_{\mathrm{p}}$ :

(1) It is found from the comparison between specimen B3.0-350-0 with bending moment ratio $M_{2} / M_{1}=0$ and specimen B3.0-350-1 with $M_{2} / M_{1}=1$ that $M_{\mathrm{u}}$ decreases from $251.5 \mathrm{kN} \cdot \mathrm{m}$ to 205.1 $\mathrm{kN} \cdot \mathrm{m}$, and $M_{\mathrm{u}} / M_{\mathrm{p}}$ also decreases from 1.17 to 0.97 when bending moment ratio between two ends of a beam increases from 0 to1. Therefore, It is conclude that $M_{\mathrm{u}}$ and $M_{\mathrm{u}} / M_{\mathrm{p}}$ decrease as bending moment ratio between two ends of a beam increases.

(2) It shows from the comparison between specimen B4.2-350-1 with height-to-thickness ratio of web $h_{\mathrm{w}} / t_{\mathrm{w}}=55.7$ and specimen B4.2-400-1 with $h_{\mathrm{w}} / t_{\mathrm{w}}=64.0$ that $M_{\mathrm{u}}$ is less affected from $206.9 \mathrm{kN}$. $\mathrm{m}$ to $210.5 \mathrm{kN}$. m by $h_{\mathrm{w}} / t_{\mathrm{w}}$. However, $M_{\mathrm{u}} / M_{\mathrm{p}}$ decreases from 0.97 to 0.83 as $h_{\mathrm{w}} / t_{\mathrm{w}}$ increases from 55.7 to 64.0 .

(3) It is found from the comparison between specimen B3.0-350-1 with lateral slenderness ratio of compressive flanges $l / r_{\mathrm{y}}=83.1$ and specimen B4.2-350-1 with $l / r_{\mathrm{y}}=116.4$ that $M_{\mathrm{u}}$ is less affected from $205.1 \mathrm{kN} \cdot \mathrm{m}$ to $206.9 \mathrm{kN} \cdot \mathrm{m}$ by $h_{\mathrm{w}} / t_{\mathrm{w}}$, and $M_{\mathrm{u}} / M_{\mathrm{p}}$ also is less affected by $h_{\mathrm{w}} / t_{\mathrm{w}}$. So, $l / r_{\mathrm{y}}$ has little influence on $M_{\mathrm{u}}$ and $M_{\mathrm{u}} / M_{\mathrm{p}}$ when $l / r_{\mathrm{y}}$ is large.

\section{Failure Mode}

As shown in Figure 4, two types of failure mode namely distortional buckling and local buckling occurred. All the specimens in the moment case $M_{2} / M_{1}=1$ (specimenB3.0-350-1, B4.2-350-1 and B4.2-400-1) encounter distortional buckling. Because of moment gradient, specimen B3.0-350-0 in the moment case $M_{2} / M_{1}=0$ encounters local buckling.

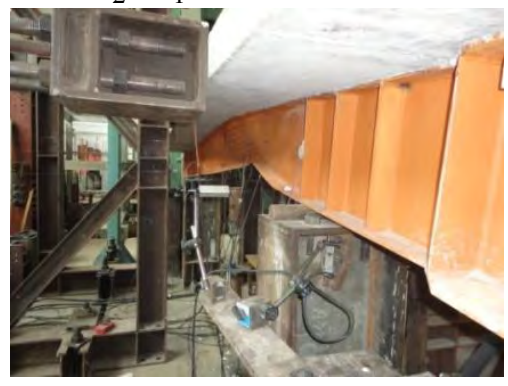

(a) Distortional buckling (specimen B3.0-350-1)

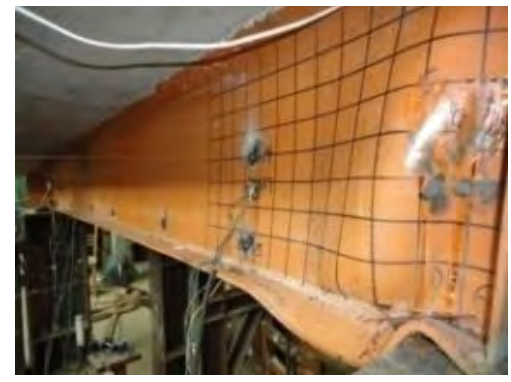

(b)Local buckling(B3.0-350-0)

Fig. 4 Failure Mode

\section{Finite Element Model and Verification of the Model}

\section{Finite Element Model}

The FE software package Abaqus v6.10 was used in the present study. Finite element model is single beam with rigid plate at two ends of a beam to apply the bending moments $M_{1}$ and $M_{2}$. As shown in Figure 5, the webs and flanges were modelled by four-node thin shell thin S4R with reduced integration points using six degrees of freedom per node. Eight-node solid elements 
C3D8R were employed to model concrete slab. Strut elements T3D2 were employed to model the steel reinforcement bars which were embedded in the concrete slab. A group of connection elements CONN3D2 were employed to model the studs between the concrete slab and steel top flange. Rigid elements R3D4 were employed to model rigid plate at two ends of a beam.

A tri-linear curve was used to describe the stress-stain relationship for the H-shaped steel beam. A bi-linear curve was employed to describe the stress-stain relationship for the rebars. The stressstrain relation for the concrete in compression and tension was the model proposed by Chinese code for design of concrete structures (GB50010-20010). The model properties were directly adopted from the measured values of experimental specimens.

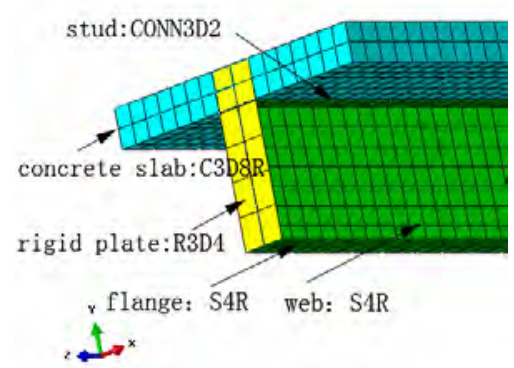

Fig. 5 Finite Element Model

Initial geometric imperfection was adopted from the first mode of elastic buckling. The maximum amplitude of geometric imperfections in the steel bottom flange used in the finite element analysis is limited to $1 / 1000$ of span. Residual stress pattern for the welded plated steel sections was considered in the nonlinear buckling analysis.

Newton's iterative technique was used to analyze the nonlinear response of the composite beam under displacement.

\section{Verification of the Model}

Figure 6 illustrates the comparison of moment-rotation curves between FE analysis and experiment of four composite beam specimens. It can be seen that the curves derived from the nonlinear finite element analysis agree well with the experimental curves.

The bending bearing capacity $M_{\mathrm{u}}$ measured in the experiments and FE analysis are also given in Table 4. The maximum relative error between the results of test and theory is less than $10 \%$.

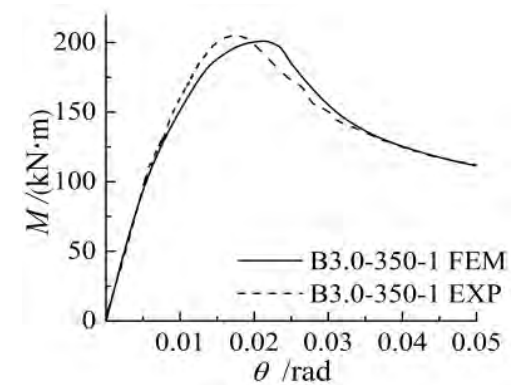

(a) Specimen B3.0-350-1

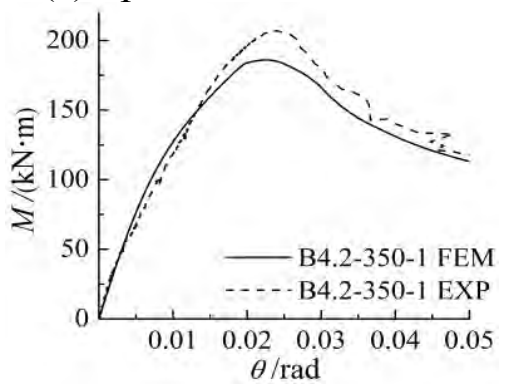

(c) Specimen B4.2-350-1

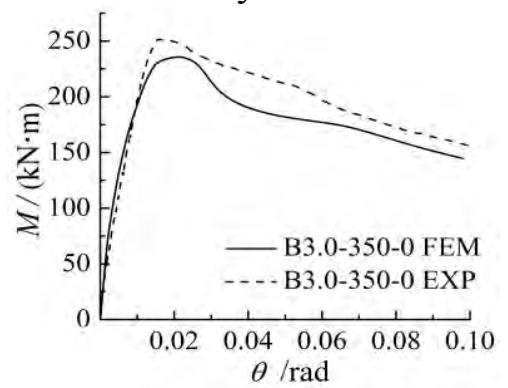

(b) Specimen B3.0-350-0

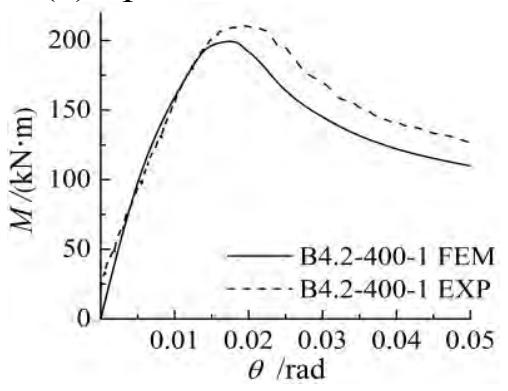

(d) Specimen B4.2-400-1

Fig. 6 Comparison of Moment-rotation Curves between FE Analysis and Experiment 
Tab. 4 Comparison of Bending Bearing Capacity between FE Analysis and Experiment

\begin{tabular}{ccccc}
\hline Specimen & $\begin{array}{c}M_{\mathrm{p}} \\
(\mathrm{kN} \cdot \mathrm{m})\end{array}$ & $\begin{array}{c}M_{\mathrm{u}, \mathrm{EXP}} \\
(\mathrm{kN} \cdot \mathrm{m})\end{array}$ & $\begin{array}{c}M_{\mathrm{u}, \text { FEM }} \\
(\mathrm{kN} \cdot \mathrm{m})\end{array}$ & $\begin{array}{c}M_{\mathrm{u}, \mathrm{FEM}} \\
M_{\mathrm{u}, \mathrm{EXP}}\end{array}$ \\
\hline B3.0-350-1 & 212.2 & 205.1 & 201.3 & 0.98 \\
\hline B3.0-350-0 & 214.7 & 251.5 & 235.7 & 0.94 \\
\hline B4.2-350-1 & 213.9 & 206.9 & 186.0 & 0.90 \\
\hline B4.2-400-1 & 253.3 & 210.5 & 199.4 & 0.95 \\
\hline
\end{tabular}

It can be seen from the above comparison that the FE model is reliable in analyzing mechanical behaviour of composite beams under negative bending.

\section{Summary}

From experimental Investigation and FEM analysis for mechanical behaviour of composite beams under negative bending, it was found as the follows:

(1)Bending bearing capacity $M_{\mathrm{u}}$ decrease as bending moment ratio $M_{2} / M_{1}$ between two ends of a beam increases. Distortional buckling occurred for the case that $M_{2} / M_{1}=1$. $M_{\mathrm{u}}$ was less than crosssection plastic moment of composite beam $M_{\mathrm{p}}$. However, local buckling took place for the case that $M_{2} / M_{1}=0$. The $M_{\mathrm{u}}$ was greater than $M_{\mathrm{p}}$.

(2)As the height-thickness ratio of web decreased, $M_{\mathrm{u}} / M_{\mathrm{p}}$ decreases significantly.

(3)If lateral slenderness ratio of compressive flanges is large, $M_{\mathrm{u}}$ is less affected by lateral slenderness ratio of compressive flanges.

(4)The finite element models of four composite beams under negative bending were established. Its validity is verified by the experimental findings. It shows that finite element method is versatile and efficient in analyzing mechanical behaviour of composite beams under negative bending.

\section{References}

[1]Daniels J. H., Fisher J. W. Static behavior of continuous composite beams. Bethlehem, PA: Lehigh University. Fritz engineering Laboratory Report No.324.2, 1967:1-85.

[2]Johnson R.P. Distortional lateral buckling of continuous composite beams. Proceedings of the institution of civil engineers, London:Thomas Telford Services 1td, 1991:131-161.

[3]Bradford M.A., Johnson R.P. Inelastic buckling of composite bridge girders near internal supports. Proceedings of the institution of civil engineers, London:Thomas Telford Services ltd, 1987:143-159.

[4]Kemp A. R. Inelastic local and lateral buckling in design codes. Journal of structural engineering, 1996, 122(4): 374-382.

[5]ZHU Pinru, GAO Xiangdu, WU Zhengsheng. Research on plastic hinge behaviour and internal moment redistribution in steel concrete continuous composite beam. Journal of Building Structures, 1990,11(6): 26-37.(in Chinese)

[6]FAN Jiansheng, NIE Jianguo, YE Qinghua, WANG Ting. Experimental Study on Moment Redistribution of Continuous Composite Steel-Concrete Beams with Profiled Sheeting. Journal of Building Structures, 2001, 22(2): 57-61. (in Chinese)

[7]LIU Yang, TONG Lewei. Numerical analysis of rotation capacity of steel-concrete composite beam under negative moment. Proceeding of The 12th national symposium on advanced structure engineering. Beijing: Industrial Construction Magazine Agency, 2012: 976-981.(in Chinese) 